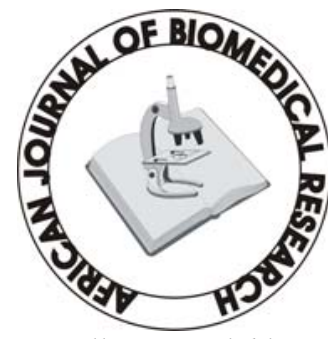

Full-text available at http://www.ajbrui.com

http://www.bioline.br/md

Received:

April, 2005

Accepted (Revised):

May, 2005

Published

January, 2006
Mini Review

\section{Application of Computers in Biochemical Education - The African Challenge}

\section{*Nyerhovwo J. Tonukari}

Department of Biochemistry, Delta State University, P.M.B. 1, Abraka, Nigeria.

\section{ABSTRACT}

Digital illustration of biomolecules and the use of computers and projectors in lectures can improve students understanding of the subject. Lecturers and students alike now rely upon the Internet to communicate and to learn new information. Digital libraries are offering a wealth of information to a large community of users and will become an increasingly valuable part of the Internet as they are developed in a coherent and imaginative way. By accessing online resources, faculty can also bring more of the dynamic nature of genomics and bioinformatics to students (Afr. J. Biomed. Res. 9:11 - 13, January 2006)

Keywords: Biochemical education, computer, digital library, Internet, genomics, bioinformatics

*Address for Correspondence: tonukari@deltastate.net 


\section{INTRODUCTION}

Students need to acquire skills to develop scientific argument, design an experimental approach to test a hypothesis, obtain and analyse data, and effectively communicate their ideas and findings to the scientific community. Most lecturers frequently conduct literature searches and access online tools found at the National Center for Biotechnology Information (NCBI). Students often search for information using Web search engines such as http://www.google.com, but biological information is accumulating so rapidly that students will need to know how to access online scientific resources if they are to be literate in biochemistry.

In order to achieve the above in our world today, both lecturers and students need to be well versed in the use of computers. The rapid expansion occurring in World-Wide Web activity is beginning to make the concepts of 'global hypermedia' and 'universal document readership realistic objectives of the new revolution in information technology (Aiton, 2004). One consequence of this increase in usage is that educators and students are becoming more aware of the diversity of the knowledge base which can be accessed via the Internet. Although computerized databases and information services have long played a key role in bioinformatics, these same resources can also be used to provide core materials for teaching and learning. The large datasets and archives that have been compiled for biomedical research can be enhanced with the addition of a variety of multimedia elements (images, digital videos, animation etc.).

\section{Digital Illustration}

Among the most difficult aspects of biochemistry for the student to master are the three-dimensional (3D) nature of biomolecules and the interaction of these substances with 3D targets such as in enzyme-ligand interaction or the structure of the DNA double helix. Compounding this problem is the fact that such relationships are very difficult to illustrate in a lecture or discussion format. While skeletal molecular models serve a useful role in the learning process, the techniques of PCbased desktop molecular visualization provide a more powerful and effective alternative to the lecture format (Henkel, 1991). The approach has found considerable use in several areas, including the generation of computerbased lecture aids. Another related technique, molecular animation, has proven to be quite successful at illustrating the essentials of enzyme mechanisms in the classroom (Henkel, 1991).

In order to provide such molecular visualization, there must be investment in computers, digital projectors, and screens. Computer training for faculty ought to be mandatory and refresher short courses should precede conferences and symposia. No matter our anxiety about computers, we may have no option but to embrace this technology.

\section{Digital Library}

With the rapid pace of science publication, it is difficult for lecturers to keep up to date in their chosen fields. PubMed (http://www.ncbi.nlm.nih.) is a productive way to search for key words or authors. As part of my lectures, I have adopted a user-intense-learning experience that encourages students to develop skills in computer access to the literature. Groups of students were required to do on-line literature searching in PubMed, and to write a short review about applications of the course or specific advanced topics. These online resources provide students with exciting entree as well as to obtain current information in order to understand and interpret the rapidly changing field of biochemistry and molecular biology. I have often emphasized to my students that the most efficient method of obtaining such information was by searching the scientific literature via computer. Several investigators have also elaborated on on-line literature search (Proud et al., 1989). I am also developing a bioinformatics course that incorporates many of the public-domain databases, research tools, and peerreviewed journals.

By definition, libraries collect information for both current and future needs of users. Preservation must also ensure that information resources remain intact. For many, the term digital library conjures up an image of a sprawling universe of information available through the Internet and accessible via home or office workstations, fulfilling the promise to provide information at any time, to any place, and for any user. Many consider the World Wide Web to be "the" digital library. Digital libraries should have a coherent, organizing principle, sorting materials by topic or by type of material, for instance.

Digital libraries offer new opportunities to enhance the value of collections to users. The best digital library currently available to the research biochemist is the NCBI's PubMed, and like many Internet sites is open and free of charge. Private digital libraries such as Institute for Scientific Information have limiting access to subscribers or to those who pay a per usage fee. Some of these are available on compact disks (CDs). Documents on these digital libraries has information about itself built into it in a standard format (metadata), that allows users to search and retrieve information more efficiently.

\section{Bioinformatics and Genomics}

Most faculty lack formal training in genomics, but students are eager to learn about this subject and its 
impact. Notwithstanding, several professors and lecturers are quickly learning to incorporate various aspects of genomics into their curriculum, either by developing new molecular biology courses or by incorporating bits and pieces of data into existing courses. However, the field of genomics is more than a compilation of lessons learned. Genomics is a dynamic body of information that can be searched and explored by anyone with Internet access.

Genomics also offers faculty new opportunities to establish collaborations in research and teaching. It is also ideal for designing challenges that will assist students in achieving these more involved cognitive capabilities. Publicly accessible databases and publications contain information that students can mine to make their own discoveries. DNA sequences, gene annotations, protein structures, protein interaction data, gene expression profiles, genomic variations, and biomedical publications are freely available online. These databases are used regularly by researchers, and students can learn to use them in their course work. Public databases permit students to conduct discovery research in their courses and provide opportunities for the lecturer to integrate research and teaching. Furthermore, students are learning valuable cognitive skills that will prepare them for real jobs. For example, undergraduate students could be asked to "describe the protein that is encoded by the SNF1 gene?” In order to answer this question, the student must learn how to search for the gene, translate DNA in amino acid sequence as well as query for the function of protein. Other information that can be obtained from such question includes the length of the protein, its hydrophobic/hydrophilic nature, subcellular localization, presence/absence of signal peptide, and motifs (Tonukari et al., 2000). Faculty can benefit twice from the time spent preparing for class when they write test questions that require students to access genomic data related to their research. Because students model behavior they observe, if faculty improve their teaching and research simultaneously, then the next generation of faculty will believe that teaching and research are mutually beneficial rather than mutually exclusive (Campbell, 2003).

Current efforts to increase the ability of African scientists to computationally process and analyse genomic and post-genomic data have the potential to produce excellent scientists who perform cutting-edge, hypothesisbased research, and who will accelerate the continent's scientific and technological development. An increasing number of universities in Africa that offer courses in life sciences are now teaching bioinformatics modules or courses (Masiga and Isokpehi, 2004).

\section{Online Publication}

Scientific inquiry thrives only in a society that fosters the free flow of ideas and information. The power of online (internet) publication in democratizing science and incorporating scientists from developing countries into the scientific community is profound. The desired and obvious properties of scientific publishing such as accessibility, economy, quality, innovation, and retrieval can be more readily achieved with electronic methods. Online publication is much cheaper and faster (Tonukari, 2004). Research papers can be converted easily into case studies for teaching. Online access to papers facilitates the use of real data and figures for reading assignments and classroom lectures. Students benefit when they learn how to interpret real data. Faculty benefit from the dual use of the time spent reading for their research and preparing for class (Campbell, 2003).

Furthermore, the recent movement to deliver scientific publications freely has presented a second source of current information for teaching. There is need for faculty to contribute papers to open access journals because of the obvious benefit of the availability of full texts. Many journals are now published freely online and everyone with access to a web browser will have free electronic access to the full text (in both HTML and PDF) of the articles.

\section{Perspectives}

The use of this digitally stored information in structured and self-directed learning environments is likely to increase as activity across World-Wide Web increases (Aiton, 2004). The scientific establishment is very much aware of the importance of computers in modern education, and some positive steps towards widespread adoption must be encouraged. Institutions should take responsibility for building digital collections of various types and then share those collections with others, thus optimizing the advantages of the distributed nature of the Internet. Subject experts in each area can assemble the collections, which will then be combined to form large digital libraries maintained by institutions for their clientele and the global Internet community.

However, computer application in biochemical education is still in its infancy in Nigeria. At the graduate and undergraduate levels, computers ought to be made available even in the laboratories so that students can easily enter and analyze data as well as prepare reports. Computer science courses taken by biochemistry students must be designed to include applications such as Microsoft office and the Internet. In order to create, disseminate, and organize information, we plan to print our students' thesis on CDs so that they can be easily searched to find information. We may also include full texts of all publications of lecturers. Ultimately, we will upload these reports into the internet and provide our 
students and other users with search tools they need to find information.

Acknowledgement: I am grateful to Prof. G.O.C. Onyeze, Acting Head, Department of Biochemistry, Delta State University, Abraka, Nigeria, for his encouragement in preparing this manuscript.

\section{REFERENCES}

Aiton, J. F. (1994) The World-Wide Web: an interface between research and teaching in bioinformatics. Dis. Markers 12(1):3-10.

Campbell, M. A. (2003) Public Access for Teaching Genomics, Proteomics, and Bioinformatics. Cell Biol Educ. 2: 98-111.

Henkel, J. G. (1991) PC-based molecular modeling in the classroom: applications to medicinal chemistry and biochemistry. J. Mol. Graph. 9(1):11-7, 34-35.
Lopez, R., Duggan, K., Harte, N., Kibria, A. (2003) Public services from the European Bioinformatics Institute. Brief Bioinform. 4(4):332-340.

Masiga, D. K., Isokpehi, R. D. (2004) Opportunities in Africa for training in genome science. Afr. J. Biotechnol. 3 (2):117-122.

Proud, V. K., Schmidt, F. J., Johnson, E. D., Mitchell, J. A. (1989) Teaching human genetics in biochemistry by computer literature searching. Am. J. Hum. Genet. 44(4):597-604.

Tonukari, N. J. (2004) Research communications in the 21st century. Afr. J. Biotechnol. 3 (2):123-126.

Tonukari, N. J., Scott-Craig, J. S., Walton, J. D. (2000). Cochliobolus carbonum SNF1 gene is required for cell wall degrading enzyme expression and virulence on maize. Plant Cell 12(2):237-248. 